\title{
CORRESPONDENCE
}

6

Correspondents are asked to be brief

Smoking in Hospitals

K. P. Ball, F.R.C.P.

Active Management of Labour

J. S. Crawford F.

Intensive Care in a District General

Hospital

G. S. Crockett, F.R.C.P..........4

Radiological Evaluation of Pulmonary Metastases

A. W. O'Malley, M.B., D.M.R.D., and M. R. P.

Shaw, M.B., D.M.R.D............ 454

Tests of Acupuncture

Sir Robert Macintosh, D.M., F.F.A.R.C.S. . . 454

Surgical Wound Infections

A. V. Pollock, F.R.C.s. . . . . . . . . . . 454
Late Advertising of Hospital Posts

D. H. Wright, M.B.; A. S. Aldis, F.R.C.S. . . 455

Promotion of Research on Deafness

H. A. Beagley, F.R.C.S., and others. . . . . . . 455

Irradiation of C.N.S. in Leukaemia

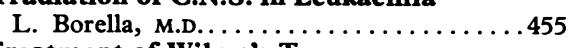

Treatment of Wilms's Tumour

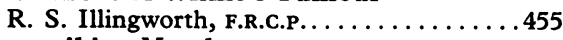

Prescribing Mandrax

W. W. Sargant, F.R.C.P...............455

G.P.s' Direct Referrals for Barium-meal Examinations

J. K. Millar, F.R.C.P.(C.), F.F.R. . . . . . . 456

Vocational Training and the R.C.G.P.

W. White, M.B.................456
Diazepam Suppositories in Prolonged

Convulsions

A. F. Conchie, M.B., D.C.H., and G. R. Lowis,

F.P.S. . . . . . . . . . . . . . . . . . .4456

Heat and the I.U.C.D.

B. Sandler, M.D................456

Traveller's Ankle

A. S. R. Peffers, M.B............446

Legal Aid and Tribunals

E. W. Shepherd, F.R.C.PSYCH..........456

Return to Work

Frances E. Mace. .

Earnings of G.P.s and Consultants

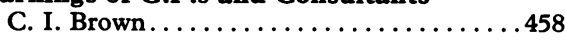

\section{Smoking in Hospitals}

SIR,-It has been estimated that about 8,500 in Britain are occupied as a result of cigarette smoking. ${ }^{1}$ The Department of Health and Social Security states that the expenditure on hospital beds due to smoking is currently $£ 25 \mathrm{~m}$. a year. ${ }^{2}$ Since there are 190,000 hospital beds in this country, this shows that every 800-bed general hospital is spending at least $£ 100,000$ each year on the results of this habit. Yet despite this evidence little is done to discourage smoking in many hospital wards, which is needed both in order to help patients who need to stop and for the benefit of nonsmokers who prefer fresh air.

For the past 20 years at this hospital we have insisted that the chest and heart wards should be no-smoking areas. Many patients appreciate the opportunity given them to stop, and complaints have been very few. Over half our patients discharged after a coronary attack who had been cigarette smokers have stopped a year later. This simple preventive measure should be enforced in all acute medical and surgical wards. Those heavily addicted or with incurable disease, where depriving them of

cigarettes would be inhumane, should be segregated from other patients.

Many hospitals still sell cigarettes in their shops and even sell them on trolleys visiting wards where there are patients with cigarette-induced diseases. At this hospital, on the advice of the medical committee, the League of Friends agreed to stop selling cigarettes two years ago in their shop. Despite initial fears by some people, the profits made have not been affected by this move.

As a profession, it is time we took a much more aggressive attitude against this cause of so much disease. As a start all hospitals should agree to stop selling cigarettes in their shops and to be much more active in discouraging smoking in their wards.-I am, etc.,

\section{Central Middlesex Hospital,}

KeIth P. Ball London N.W.10

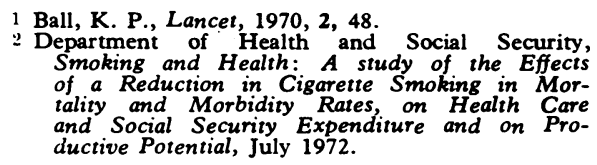

\section{Active Management of Labour}

SIR,-Few engaged in the clinical care of the obstetric patient will not support the advocacy by Professor Kiernon O'Driscoll and his colleagues (21 July, p. 135) of the active management of labour. The era when a long and dreary labour was accepted as a normal variant, interference with which was categorized as meddlesome obstetrics, should be long past. One doubts, of course, that your contributor's arbitrary definition of 12 hours as being the acceptable period for primigravid labour is necessarily correct, but it need not be cavilled with at the moment.

I fail completely, however, to understand the authors' claim that the institution of a policy of active management "places the problem of pain in a new setting." I believe that your contributors are guilty of confusing the condition of pain with that of exhaustion. A painful labour tends, without the aid of stimulation, to become a long and exhausting labour (though mothers have been observed to be exhausted after an unrelieved labour of only 3-4 hours). In my view, however, patients (specifically primigravidae) are little concerned about the duration of labour, but are concerned about the pain involved. This latter attitude is hardly a new phenomenon induced, as suggested by Professor O'Driscoll, by the propaganda of anaesthetists and other "do-gooders." It has been known through untold ages by womankind that, for the majority, labour is a painful process-or do your contributors contend that it is "all in the mind," and advocate a universal return to the messianic exhortations of Grantly Dick Read? I am utterly at a loss to understand why adequate pain relief should not be provided during the course of an actively managed labour. I am prepared at any time and in any place to substantiate my claim that in the majority of cases such labours are painful.

Adequacy of relief may be provided by pethidine, intermittent inhalational analgesia, or an epidural block. I advocated a "loading dose" of $150 \mathrm{mg}$ pethidine ${ }^{1}$ because I believed that such a regimen offered the better prospect of gaining the patient's confidence in the efficacy of the drug, but I accept that a small proportion of patients find the response unpleasant. (The reference to "hard drugs" puzzles me-I doubt that many of our obstetric patients in he U.K. have previously had more than one dose of a narcotic). My own preference is outstandingly for the application of an epidural block. The analgesia is, both quantitatively (in respect of the incidence of successful pain relief) and qualitatively (in respect of the "total success" rate and the absence of disconcerting clouding of the sensorium), superior by far to the other available techniques. In addition, an epidural block carries the bonus of being beneficial to the feuts. ${ }^{2}$ It has been conclusively demonstrated ${ }^{2}$ that the fetus of the mother who does not have an epidural block (and does or does not have some other form of analgesia) becomes progressively more acidotic throughout the established first stage of labour, whereas the acid-base status of the fetus whose mother has had an epidural block does not deteriorate. Furthermore, the end-result-the delivered infantof the "epidural case" is in a better condition both biochemically and clinically than is the infant of the "non-epidural" mother. ${ }^{3}$ The differences are admittedly of little moment in respect of patients without obstetric pathology, but they are worthy of serious consideration in cases in which the fetus is at risk (pre-eclamptic toxaemia, maternal diabetes, small-for-dates fetus, $\mathbf{R h}$ incompatibility, and the like). It is true that Professor O'Driscoll and his colleagues claim to have considered epidural block for patients who "were distressed soon after admission," "were not close to full dilatation after six hours," or "suffered from special diseases such as toxaemia or heart disease." However, as only 53 patients came into one or other of these categories $(5 \cdot 3 \%$ of a consecutive series of 
primigravide) one wonders how your contributors define toxaemia.

There are several non sequiturs in the text which others among your readers will doubtless wish to question. I would only ask why, when they show themselves to be so progressive in their approach to the active management of labour, your contributors are so adamantly retrogressive in their attitude towards the management of pain in labour? -I am, etc.,

J. Selwyn Crawford

Birmingham Maternity Hospital,

Birmingham

1 Crawford, J. S., Principles and Practice of $\mathrm{Ob}$ stetric Anaesthesia, 3rd edn. Oxford, Blackwell, 1972.

2 Pearson, J. F., in Proceedings of Symposium on Epidural Analgesia in Obstetrics, ed. A. 3 Crawford, J. S. S., Davies, P., and Pearson, J. F., British łournal of Anaesthesia, 1973, 45, 148.

\section{Intensive Care in a District General Hospital}

SiR,-The article by Dr. A. R. Tanser and Mr. B. G. Wetton (28 July, p. 227) on their experience with a multipurpose intensive care unit underlines not only the quality of care that it is now possible to provide in a district general hospital but also the stimulating effect that such a unit has on the nursing and medical care in the rest of the hospital.

A similar four-bedded unit has now been running at Kettering General Hospital since 1963, and our experience with such a unit was described after two years. ${ }^{1}$ The admission rate has risen steadily from 217 in 1963 to 503 in 1972, the average length of stay having been reduced from 4 days 21 hours to 2 days 8 hours (56 hours)-very similar to the average length of stay (57 hours) in the unit at the St. Martin's Hospital, Bath, as reported by Dr. Tanser and Mr. Wetton. Another remarkable similarity is their finding that $62 \%$ admissions are for "Medical" conditions, our corresponding figure in 1971 being $63 \%$. There is such remarkable correspondence between the percentage of total admissions for different conditions in the two units that it seems worth while to record them:

\begin{tabular}{l|c|c}
\hline & $\begin{array}{c}\text { Bath, } \\
1968-71\end{array}$ & $\begin{array}{c}\text { Kettering } \\
1972\end{array}$ \\
\hline Myocardial infarction & 31.1 & 30.2 \\
Other cardiac disorders & 6.4 & Not available \\
Self-poisoning & 13.3 & 16.1 \\
Respiratory disorders & 12.4 & Not available \\
Surgical & 11.1 & 9.3 \\
Trauma & 10.3 & 14.1 \\
Others & 15.4 & 9.9 \\
\hline
\end{tabular}

It would seem, therefore, that those thinking of setting up such multipurpose units in district general hospitals could take these figures as a fair prediction of the cases they will admit in the course of a year, and plan accordingly.

From our system of recording each admission to the unit, which is separate from the usual hospital records, we have determined that $22 \%$ of patients are unconscious on admission and that $8.5 \%$ are admitted as a result of road traffic accidents. The overall mortality is $15 \%$. One in 20 of all hospital admissions pass through the intensive care unit. The cost of each patient's stay is $£ 60$, a small price to pay for a life, for if admitted to any other ward they would almost certainly die. Of this $£ 60$, the majority of the cost is in nurses' salaries-£46; 112 goes for drugs and dressings and the remaining £2 for heating, lighting, and food. Nothing extra is allowed for doctors' salaries, which would be the same were there no intensive care unit.

I hope there are few district general hospitals in the United Kingdom without such a unit. If there are, I would strongly urge them to get on with building one on the lines of the unit at Bath. The impetus to build the unit must come from the medical staff, and some enthusiast must be found to be in administrative charge; "for nothing great was ever achieved without enthusiasm" (Emmerson $\left.{ }^{2}\right)$.- I am, etc.,

Department of Medicine,

Kettering and District General Hospital
Kettering, Northants

Crockett, G. S., and Barr, A., British Medical Fournal, 1965, 2, 1173 Macmillan, 1883 . Essays, ed. J. Morley. London,
Mmerson, R. W.

\section{Radiological Evaluation of Pulmonary} Metastases

SIR,-In the report by the Clinical Screening Group of the European Organization for Research on the Treatment of Cancer (28 July, p. 199) two chest radiographs were reproduced (fig. 3) purporting to show complete regression of a pulmonary metastasis from a renal carcinoma.

It is our view that from the reproductions printed it is not possible to make this claim. It would appear that the first radiograph shows multiple metastases in both lung fields with what appear to be bilateral basal effusions and a large area of consolidation adjacent to the right heart border. In the second reproduction, after treatment, the effusions have cleared and there is a reduction in size of the "consolidated area" near the right hilum, but this resolution is not complete. The multiple metastases are still present though they do not coincide exactly with those on the first film.

It would seem that while there has been considerable improvement with treatment the caption indicating "complete regression of a pulmonary metastasis" is misleading.-We are, etc.,

$X$-ray Department,

A. W. O'MALley

Tespital Centre,

Department of Radiodiagnosis,
University Hospital of Wales,

Michael SHAW Univers

\section{Tests of Acupuncture}

SIR,-As a means to prevent pain in surgery I have no doubt that acupuncture worksBut (with a capital B) only in a limited range of surgery, and in a very, very limited number of patients; and in this respect it differs not at all from hypnotism, mesmerism, suggestion, animal magnetism, call it what you will. The idea that acupuncture can be grouped with general anaesthetics and local analgesics, or that currently it "is em- ployed for most of the major surgery that is undertaken on the Chinese mainland nowadays" (Dr. P. E. Brown 30 June, p. 780) is, in my opinion, nonsense.

At the suggestion of Mr. J. S. Horn, F.R.C.S., I had the good fortune to be invited by the Chinese Medical Association and spent eight weeks in the autumn of 1959 on an anaesthetics lecture/demonstration tour in that country. I travelled extensively, visiting Peking, Changchun, Shenyang (Mukden), Anshan, Sian, Chungking, Wuhan, Shanghai, Hangchow, and Canton. I had with me a dictating machine of which my hosts approved, and which indeed on one occasion they repaired though they were unfamiliar with it. I made on-the-spot notes and dictated freely from these on my return to the hotel. Transcription of the dictation belts was made in England as the result of which I have a diary of 430 typewritten quarto pages. I had the advantage of having the same personal interpreter throughout, Dr. Shang, senior anaesthetist at the Peking Chest Hospital who had in 1948-9 spent 12 months with an internationally known anaesthetist in mid-America. He proved helpful, pleasant, and well informed. I received the most courteous and considerate treatment everywhere and came away, like every other visitor I have heard of, enormously impressed by what had been accomplished in that great country. This visit of mine changed most of my preconceived ideas about China, but not about acupuncture, of which, at my request, I saw quite a lot, and made full notes.

In brief, I saw nothing done under acupuncture more remarkable than the surgery described and illustrated in the book by Esdaile ${ }^{1}$ published in 1846, just before the introduction of ether.

All these operations were carried out with the help only of mesmerism. I could cite many other contemporary references. A quite recent article in Anaesthesia, the official journal of the Association of Anaesthetists, was entitled "Surgery under Hypnosis." In this we read that in Britain two impacted wisdom teeth requiring incision of gum and use of bone chisels "were removed completely painlessly under hypnosis." Also in the same patient, but on a different occasion, a bilateral mammaplasty was successfully carried out under hypnosis. At one point the patient "remarked that she was thirsty and was given a drink with a feeding cup while the operation continued." During surgery under acupuncture munching orange segments is currently more favoured. ${ }^{35}$ It is noteworthy that the above article excited no comment. Were the procedures to be repeated now, with benefit of acupuncture, I have little doubt they would hit the headlines both lay and medical.

In China I formed the impression that specific acupuncture points, at any rate those unrelated of gross anatomy, were phoney, and that the same results, good and disappointing, would have followed had the needles been inserted elsewhere. And I have no doubt that my views were shared by my Chinese colleagues who had received an orthodox ("Western" to them) medical training. But my colleagues were loyalists. They were not concerned whether the procedure was well founded scientifically; what mattered was whether it was good for their country. The more I learnt about the recent history 